\title{
O humano em Søren Kierkegaard e em Viktor Frankl
}

\author{
The human in Søren Kierkegaard and Viktor Frankl
}

\author{
Glenda Matias de Oliveira Rosa \\ Lúcia Helena Cavasin Zabotto Pulino \\ Universidade de Brasília \\ Brasil
}

\begin{abstract}
Resumo
Este trabalho é um estudo teórico que objetiva abordar aspectos centrais da Antropologia Filosófica presentes em dois autores existencialistas: Søren Kierkegaard e Viktor Frankl. A partir do estudo do que é o homem, apresentamos algumas importantes questões existenciais que, embora desenvolvidas pelos autores supracitados nos séculos XIX e XX, respectivamente, permanecem atuais: 0 desespero e a busca pelo sentido, liberdade, responsabilidade, possibilidade e necessidade, angústia e vazio existencial. Partimos da pesquisa qualitativa, por meio de uma revisão de literatura, buscando atender ao objetivo proposto. Compreendemos que a dimensão do espírito diferencia o homem dos outros seres. Ambos os autores destacam a esfera espiritual e compreendem o humano em sua integralidade. Conclui-se que Kierkegaard e Frankl, em seus pressupostos, oferecem possibilidade de conhecimento do homem e de questões existenciais relevantes para nossa sociedade permeada pelo desespero e pelo vazio existencial. Assim, as proposições dos autores contribuem especialmente para as ciências humanas.
\end{abstract}

Palavras-chave: antropologia filosófica; Viktor Frankl; Søren Kierkegaard; existencialismo.

\begin{abstract}
This paper is a theoretical study that aims to approach central aspects of Philosophical Anthropology present in two existentialist authors: Søren Kierkegaard and Viktor Frankl. From the study of what man is, we present some important existential questions that, although developed by these authors in the nineteenth and twentieth centuries respectively, remain current: despair and the search for meaning, freedom, responsibility, possibility and necessity, anguish and existential void. We started from the qualitative research, through a literature review seeking to meet the proposed objective. We understand that the dimension of the spirit differentiates man from other beings. Both authors highlight the spiritual realm and understand the human in its entirety. We conclude that Kierkegaard and Frankl, in their assumptions, offer the possibility of knowledge of man, and of existential questions relevant to our society, which is permeated by despair and existential emptiness. Thus, the authors' propositions contribute especially to the humanities.
\end{abstract}

Keywords: philosophical anthropology; Viktor Frankl; Søren Kierkegaard; existencialism.

\section{Introdução}


O presente trabalho tem por objetivo abordar aspectos centrais da Antropologia Filosófica presentes em dois autores existencialistas a saber: Søren Kierkegaard e Viktor Frankl, realizando um paralelo entre o pensamento de ambos os autores. A partir do estudo do que é o homem, apresentamos no presente artigo algumas questões existenciais que, embora desenvolvidas pelos autores supracitados nos séculos XIX e XX respectivamente, se mostram cada vez mais atuais em nossa sociedade: o desespero e a busca pelo sentido, liberdade, responsabilidade, possibilidade e necessidade, angústia e vazio existencial. A partir dessa compreensão acerca do ser humano, partimos de uma investigação caracterizada como uma pesquisa qualitativa, por meio de uma revisão de literatura.

O questionamento sobre o sentido da vida é, antes de tudo, essencialmente humano. Ter uma vida significativa, seja em qual fase do desenvolvimento o sujeito estiver, é algo extremamente importante. De acordo com Miguez (2015), faz-se necessário considerar a realidade total e singular humana enquanto ser existente, um ser que "sempre aponta para além de si mesmo, em busca permanente de sentido" (p.10). Vivemos em uma sociedade globalizada, que, apesar de ter desenvolvido avanços tecnocientíficos, acabou por fragmentar os campos do conhecimento. Essa fragmentação, sem dúvida, acaba por produzir forte impacto na subjetividade humana e na sua forma de ser e estar no mundo. A tônica do individualismo, da competição e da alta exigência de produtividade têm formado pessoas cada vez mais vazias de sentido. O questionamento inicial nunca se fez tão presente e tão necessário. Não queremos dizer aqui que o homem se pergunta pelo sentido da vida apenas quando se vê cercado de limites, pois, de acordo com Dourado e colaboradores (2010, p.82) "indagar pelo sentido da vida não significa dizer que o homem está doente, mas sim que expressa o que há de mais humano em si".

Inicialmente, para alcançar o objetivo proposto, julgamos necessária uma breve apresentação da biografia dos autores citados, e, em sequência, apresentaremos alguns dos importantes fundamentos teóricos de ambos, especialmente a partir do delineamento geral de Antropologia Filosófica, - entendendo que, se nos propomos a explorar as questões existenciais humanas, tão presentes em nosso cotidiano, antes se faz necessário pensarmos a respeito do conceito de humano que se tem em vista.

\section{Sobre os autores}

Søren Aabye Kierkegaard (1813-1855), filósofo e teólogo dinamarquês, possuiu marcada influência sobre a ética cristã. Nota-se que não há um consenso claro quanto ao fato de ser considerado um filósofo existencialista, já que alguns o consideram como um filósofo pós-modernista, humanista ou individualista. Kierkegaard teceu 
críticas ao hegelianismo, principalmente no que dizia respeito ao "direito de ignorar a existência concreta do indivíduo" (Bessa, 2009) e à cristandade de sua época. Sua obra é vasta e "surpreende o leitor por sua força" (Gouvêa, 2000, p. 225), passando por temas da religião, e transitando pela literatura e política. O autor lançou mão do uso de pseudônimos para assinar suas obras. A obra: La enfermedad mortal, publicada originalmente em 1849, é assinada pelo pseudônimo Anti-Clímacus, marcadamente cristão. O título retoma a fala de Jesus sobre Lázaro: "esta enfermidade não é para a morte" (Jó 11, 4). Anti-Clímacus, portanto, intenta abordar questões relativas aos aspectos do eu, da interioridade. Questões acerca do espírito humano.

Viktor Emil Frankl (1905-1997), por sua vez, foi um psiquiatra vienense, neurologista, psicoterapeuta e doutor em filosofia. Dedicou-se fortemente ao estudo do sentido da vida. O referido autor, em 1927, quando era ainda estudante de medicina, desenvolveu sua prática clínica dedicando-se a atender jovens com o objetivo de reduzir as taxas de suicídio entre a juventude de Viena. Obteve sucesso e observou a importância da busca pelo sentido da vida para a prevenção da mesma. Frankl foi o fundador de uma teoria que reverberou em vários campos do conhecimento humano: a Logoterapia e Análise Existencial. Judeu, passou pela experiência da barbárie, ao sobreviver a quatro campos de concentração nazistas.

Aquino (2013) salienta que a visão de homem e mundo de Frankl acabou por transitar entre os terrenos da filosofia, teologia, psicologia, sociologia e da educação. Ao entrarmos em contato com os escritos de Frankl, percebemos forte influência do pensamento de alguns autores, dentre eles vários filósofos existencialistas e fenomenólogos. Notamos, portanto, a influência kierkegaardiana em seu pensamento direta ou indiretamente, como curiosamente comenta o próprio Frankl:

Durante algum tempo, pensei em me dedicar à dermatologia ou à obstetrícia. Até que certo dia, outro aluno de medicina, W. Oesterreicher, que mais tarde se fixou em Amsterdã, me perguntou se eu já ouvira falar de Søren Kierkegaard. Afinal, para esse meu flerte com matérias não psiquiátricas havia uma frase de Kierkegaard: o desespero de não querermos ser nós mesmos. Na sua opinião, eu tinha muito talento para a psiquiatria e deveria aceitar esse talento. É difícil acreditar que uma observação tão simples pode às vezes operar uma transformação significativa em nossas vidas. De todo modo, a partir daí eu estava firmemente decidido a não mais fugir da "autorrealização psiquiátrica" (Frankl, 2010, p.57).

O fato é que, enquanto era ainda estudante de medicina, Frankl se dedicava à leitura de grandes filósofos, dentre eles, Kierkegaard. Assim, a partir do diálogo possível entre os pensamentos franklianos e kierkegaardianos, buscamos traçar um paralelo partindo especialmente de conceitos sobre o ser humano, e algumas de suas 
questões existenciais. Iniciaremos com o apontamento de pressupostos que compõe 0 que conhecemos por Antropologia Filosófica, sem a qual nada se pode depreender de antemão.

\section{Conceitos de Antropologia Filosófica}

É interessante notar o que salientam Silveira e Mahfoud (2008) a respeito do humano: a sua capacidade de perceber a si mesmo, de formulação do pensamento crítico, e, portanto, tais potencialidades mostram a emergência do seu nascimento existencial. O homem pode admirar-se frente à vida, e expressar sua perplexidade diante da mesma "(...) pergunta-se quem é, o que faz aqui, o que é viver, por que a vida é tão desafiadora, por que existem injustiças e sofrimento. Quer saber se a vida de que dispõe é tudo o que terá, qual o motivo de ter nascido em determinado tempo e lugar (...) pergunta-se se a própria vida faz sentido" (Silveira \& Mahfoud, 2008, p.574).

O conceito de "homem" em Kierkegaard e em Frankl parece convergir e apresentar bases comuns. Inicialmente disporemos o pensamento proposto por Kierkegaard para só então apresentarmos o pensamento de Frankl. Posteriormente, traçaremos um paralelo possível entre ambos os pressupostos.

A antropologia filosófica em Kierkegaard reflete sobre os três aspectos existenciais do homem: o estético, o ético e o religioso. Este último é, sem dúvida, primordial no pensamento do autor para compreendermos sua antropologia. Na obra La enfermedad mortal, Kierkegaard (2008) elucida que "o homem é espírito" (p.33). Para o autor, "o espírito é o eu" (p.33). Ele afirma ainda que o homem é constituído por uma espécie de movimento de voltar-se a si mesmo, emergindo assim, sobre si a junção das categorias presentes, que, mesmo que contraditórias, simultaneamente compõe sua humanidade: infinito e finito, temporal e eterno, liberdade e necessidade. Assim, Kierkegaard (2008) define o 'eu' justamente como esse voltar-se a si, como o elemento da ordem do transcendente que o constitui. Para Kierkegaard (2008), portanto, "o homem é a síntese entre infinitude e finitude, temporal e eterno, liberdade e necessidade (...)" (p.33, tradução nossa).

Farago (2006) tece considerações pertinentes a respeito da antropologia filosófica apresentada por Kierkegaard:

O axioma da antropologia kierkegaardiana é simples: ainda que todo homem se desenvolva com liberdade, não se cria a si mesmo a partir de nada: ele se recebe sob a forma de uma condição específica na qual está inserida a necessidade de se arrancar da animalidade, dando-lhe como tarefa a realizar sua pessoa concreta. Dado a si mesmo sob a forma de imediaticidade, lançado no mundo sob a forma biológica do 
corpo e de sua reverberação psíquica (a alma), deve ele chegar ao espírito, à faculdade de síntese reflexiva (p.76).

Para Kierkegaard (1986), o homem é composto de um duplo movimento, um orientado para o finito - a morte - e outro orientado para o infinito - a vida eterna, ou seja, o alvo do cristão que seria, portanto, o único ser com a possibilidade de superar a própria morte. Quando apenas um desses movimentos é concretizado, o homem se desespera. Aqui habita justamente um conceito fundamental em sua obra: o conceito de desespero, que para ele é "um sentido puramente dialético" (p.35, tradução nossa) entre vantagem e defeito. Pode ser uma vantagem, à medida que nos mostra que só pode desesperar-se aquele que possui espírito. O desespero diferencia, assim, o homem do animal irracional. Portanto, para o filósofo, "a possibilidade desta enfermidade é a vantagem do homem sobre o bruto, vantagem que nos caracteriza infinitamente mais do que andar na vertical, já que ela significa a infinita verticalidade e elevação que nos compete por sermos dotados de espírito" (p.35, tradução nossa).

Kierkegaard (1986) concebe o homem como um ser-no-mundo, que têm diante de si muitas possibilidades. O homem é, para ele, um ser responsável pelas escolhas que faz, e é a síntese de corpo, alma e espírito. A definição de homem enquanto espírito, e a afirmação de ser esta a maior diferenciação entre o homem e os outros animais, está clara no pensamento filosófico kierkegaardiano, porém, no campo da psiquiatria e da psicologia do século $X X$, especificamente no contexto da psicoterapia representado por duas das grandes e dominantes escolas vienenses de psicoterapia da época - a Psicanálise de Sigmund Freud (1856-1939), e a Psicologia Individual de Alfred Adler (1870-1937), escolas estas que advinham do positivismo científico e que partiam de uma visão cientificista, apresentavam uma visão de homem apenas considerando seus aspectos biológicos e psíquicos, deixando completamente de lado a consideração do homem enquanto espírito.

Frankl (1978) criticou veementemente a visão reducionista de homem - o que ele denominou de sub-humanismo - fortemente presente nas ciências humanas de sua época, e, de acordo com Miguez (2019, p.45), "sua análise crítica ao cientificismo da época pretendia focar, sobretudo, a insuficiência das ciências humanas para abarcar o problema antropológico da unidade e da multiplicidade do homem" (Miguez, 2019, p.45).

Cabe aqui apresentarmos a visão frankliana sobre a concepção de homem, entendendo que tal compreensão filosófico antropológica proposta pelo autor é o eixo central do sistema teórico da Logoterapia e Análise Existencial. No decorrer de toda sua obra, Frankl elabora o que podemos denominar de uma "antropologia". Porém, tal antropologia não aparece de forma sistematizada e acabada. Permanece dispersa em 
todos os seus escritos, conferindo o fio condutor de sua construção teórica, enredando em uma trama todos os outros elementos de seu pensamento.

Viktor Frankl buscou sistematizar a proposição de uma ontologia dimensional levando em consideração "as diferenças ontológicas e à unidade antropológica existente no ser humano, propondo um modelo dimensional que fosse além da teoria da construção de graus e da organização de estratos. Propõe ele, para tanto, uma abordagem more geométrico a que deu o nome de 'ontologia dimensional'" (Pereira, 2013, p.70).

Ao iniciarmos o estudo sobre a ontologia dimensional de Frankl (1978), percebemos que ele define a existência humana como unitas multiplex - terminologia proveniente da filosofia de Tomás de Aquino - ou seja, na existência humana coexistem a unidade antropológica e as diferenças ontológicas presentes. A ideia de dimensão desenvolvida por Frankl (1988) acompanha justamente a noção matemática do termo, entendendo que existem "diferenças qualitativas que não anulam a unidade de uma estrutura" (p.23). Há, portanto, uma organização dialética das três dimensões ontológicas estruturantes do homem a saber: corpo, psiquismo e espírito. Portanto, o homem para a Logoterapia, é um ser tridimensional, e a compreensão do que é o homem perpassa necessariamente pela compreensão da dinâmica dessas três dimensões ontológicas fundantes.

$\mathrm{Na}$ visão da Logoterapia, corpo, psiquismo e espírito não podem ser compreendidas separadamente, pois a "constituição de uma presume, logicamente, a da outra" (Pereira, 2013, p.71). Frankl se utiliza da metodologia chamada de "suprassunção" (Aufhebung) para tratar das três dimensões. Ou seja, ele deixa claro que não há uma categoria que seja superior à outra, no sentido de desmerecimento, hierarquia ou juízo de valor. Quando Frankl (2013) versa a respeito de uma dimensão superior, ele está chamando atenção para o fato de "uma dimensão mais compreensiva, que abarca uma dimensão inferior". A dimensão inferior é, portanto, 'elevada' à dimensão superior, exatamente no sentido plúrimo que Hegel confere a este termo (p.46), já que para Hegel, suprassunção, do verbo aufheben denota o ato de "negar, manter e elevar semanticamente" (Pereira, 2015, p.4).

Dessa forma, "a categoria do corpo é suprassumida (aufgehoben) na categoria de psiquismo, que, por sua vez, é suprassumida na categoria de espírito" (Pereira, 2013, p.71). As três dimensões estruturam a pessoa na visão da Logoterapia. Desconsiderar alguma delas, portanto, é adotar uma postura reducionista que acaba por despersonalizar o próprio homem.

Vale ressaltar que os termos "espírito" e "espiritual" presentes na obra frankliana foram aos poucos sendo substituídos pelo termo "noético", ou "dimensão noológica" noous etimologicamente é entendido por espírito - que representam a mesma ideia. 
Essa substituição ocorreu devido às confusões e mal-entendidos teóricos que se criaram em torno da palavra "espírito", especialmente nos Estados Unidos da América - e no Brasil - onde o termo traz consigo a ideia de religiosidade, ao contrário do que sugere a palavra alemã Geist. O conceito de espírito adotado por Frankl parte exatamente de um pressuposto filosófico do qual o próprio Kierkegaard lança mão. $\mathrm{O}$ espírito é o que torna o homem um ser diferente dos outros animais. É da ordem do eu. Sobre isso, Frankl (1988) esclarece:

O que nós compreendemos como dimensão noológica se refere a uma conceituação antropológica, muito mais do que teológica. O mesmo também vale para "logos", no contexto do termo "logoterapia". Além de denotar "sentido", "logos" aqui significa 'espírito' - mas, novamente, sem qualquer conotação religiosa primária. Aqui, "logos" significa a humanidade do ser humano e o sentido de ser humano! (p.17).

Frankl (2004) destaca na ontologia humana a dimensão noética entendendo que, a partir dela, o homem é livre para se posicionar frente os condicionamentos físicos e psíquicos. Ou seja, para ele, o fatídico é psicofísico e a existência é o espiritual, que possui aspectos da religiosidade, porém transcende a esfera da religião e abrange vários outros atributos humanos. É a única dimensão ontológica que não adoece. É o lado saudável do homem que deve ser evidenciado na busca de proteger as outras dimensões também importantes. Para Frankl (2004) existe uma unidade antropológica, ou seja, as dimensões se interpenetram. Esse ponto é importante ser ressaltado, já que podemos notar que o autor adota uma terminologia distinta de outros autores que também concebem a existência de um nous como estruturador do humano. Miguez (2015) reconhece que

\begin{abstract}
... a vantagem dessa terminologia que concebe o fisiológico, o psicológico e o espiritual como 'dimensões' - frente ao modelo estratificado de Nicolai Hartmann e ao de núcleos concêntricos de Max Scheler - é que os dados particulares, às vezes contrastantes, das diversas dimensões não se excluem, pelo fato de que a dimensão superior abrange, compreende sempre a inferior e, com isso, garante a continuidade dos diversos fenômenos entre si, apesar da especificidade de cada um deles. Assim, a ontologia dimensional vem salvaguardar aquela unitas multiplex (pp.62-63).
\end{abstract}

A primeira dimensão ontológica abordada por Frankl (2004) é a dimensão orgânica, que compreende nossa estrutura fisiológica e corporal. A segunda categoria humana, o psiquismo é a morada das sensações, do desejo, dos impulsos. Lukas (1989) elucida que é nessa dimensão que reside uma "consciência cognitiva, aos quais podem ser associados talentos intelectuais e padrões comportamentais adquiridos (p.28)". A psicologia se dedica fundamentalmente a estudar tal dimensão, 
que media duas outras: corpo e espírito. Frankl rompe com o dualismo proposto de mente-corpo, justamente por acreditar que o psiquismo por si só é incompatível com processos superiores do homem, tais como liberdade e responsabilidade - conceitos caros à Logoterapia - que vão muito além do funcionamento psíquico. Nas palavras do autor:

Nenhuma unidade psicossomática no homem, por mais íntima que seja, consegue constituir sua totalidade; a essa última pertence essencialmente o noético, o espiritual, porque o homem representa um ser, certamente não só espiritual, mas sim em sua essência e porque a dimensão espiritual é constitutiva para ele, enquanto esta representa a dimensão, certamente não a única, mas sim a específica, de sua existência, quer se considere o espiritual homem de maneira fenomenológica, como sua personalidade, quer de maneira antropológica, como sua existencialidade (Frankl, 1995, p. 66).

Baseando-se na filosofia de Max Scheler (1874-1928), Frankl afirma que também os animais possuem a dimensão psíquica. Volkmer (2006 citado por Pereira, 2015) sinaliza que existem níveis que o homem compartilha com os animais:

1) o impulso afetivo (ou 'sensitivo') já presente nas formas viventes vegetais; 2) o instinto animal nas formas viventes vegetais; 2) o instinto animal; 3) a memória associativa presente em certos animais; 4) a inteligência prática. É característica de todos estes processos uma progressiva individuação e desprendimento em relação ao meio natural. O homem compartilha elementos de todas estas esferas. Porém, não somente o homem, mas também animais superiores (p.6).

A dimensão noética, etimologicamente definida como "nous= espírito", conforme citado anteriormente, é especificamente humana e abrangente. Dourado e colaboradores (2010) afirmam que nela estão "a criatividade humana, a religiosidade, o senso ético, a compreensão do valor" (p.20). Para Miguez (2014), o existir, ou o "ex-sistere do indivíduo no interior da própria constituição psicofísica põe em manifesto seu caráter noético (noos: espírito) incondicionado" (p.56), ou seja, implica o sair de si mesmo, sair do âmbito psicofísico e ir em direção a si mesmo passando necessariamente pela dimensão espiritual.

Ou seja, para a Logoterapia, é na dimensão espiritual que reside a consciência moral humana, residindo também a liberdade e responsabilidade do homem. Nessa dimensão que está presente a capacidade humana de posicionar-se, decidir-se livremente frente aos condicionantes corporais e psíquicos. A dimensão noética ou espiritual abarca, portanto, "as decisões pessoais de vontade, interesse prático e artístico, pensamento criativo, religiosidade, senso ético e compreensão do valor" (Lukas, 1989, p.29). Em tal dimensão, torna-se possível um distanciamento a respeito 
de determinantes biológicos e psicológicos. É possível ao homem conferir uma resposta livre e consciente frente as imposições postas. A espiritualidade é definida por Vaillant (2010) como "o amalgama de emoções positivas que nos une aos outros seres humanos e à nossa experiência com o divino, como que o concebamos" (p.5).

A imago hominis da Logoterapia se apoia em duas leis propostas por Frankl. A primeira diz que o homem é um ser tridimensional, e que se olharmos apenas para uma ou duas de suas dimensões, não conseguiremos compreendê-lo em seu aspecto integral. A segunda lei frankliana (figura 2) nos permite entender que "a personalidade do homem é compreendida quando se leva em conta a totalidade integrada vivida pela multiplicidade dos fatores que envolvem o homem" (Aquino, Damásio, Silva, 2010, p.23). Frankl (1988) define essa lei da seguinte forma: "(...) quando diferentes fenômenos são projetos de suas dimensões particulares em uma dimensão diferente mais baixa do que a própria, as figuras que aparecerão em cada plano serão ambíguas" (p.22). Tal lei nos permite entender que "a personalidade do homem é compreendida quando se leva em conta a totalidade integrada vivida pela multiplicidade dos fatores que envolvem o homem" (Aquino, 2010, p.23).

Podemos compreender então, a partir da antropologia e ontologia dimensional de Frankl, que o homem é um ser dotado de uma unidade e totalidade biopsicoespiritual, e que quando são projetadas apenas as dimensões biológica e psicológica do seu ser, resultam fenômenos contraditórios (conforme sugere a figura 2). Considera-se apenas os fenômenos somáticos presentes no campo da biologia, e apenas os psíquicos no campo da psicologia. Porém, têm-se uma visão incompleta, amputada, reducionista do homem (notamos que, de fato, o círculo e o retângulos estão integrados no cilindro). Portanto, "a união dos opostos como soma e psyché deve ser buscada unicamente na dimensão mais elevada, a dimensão do nous: só o espiritual constitui a garantia do 'uno'"' (Miguez, 2019, p.80).

Abaixo colocaremos as figuras 1 e 2 para exemplificar as duas leis citadas acima. Sobre a figura 2, ao analisá-la, precisamos nos atentar para o fato de estar representado um cilindro, um cone e uma esfera projetados em uma mesma dimensão, projetando uma circunferência, ainda que venham de objetos distintos. Ou seja, a partir da projeção em si, não podemos conhecer o que há por sobre o círculo. 

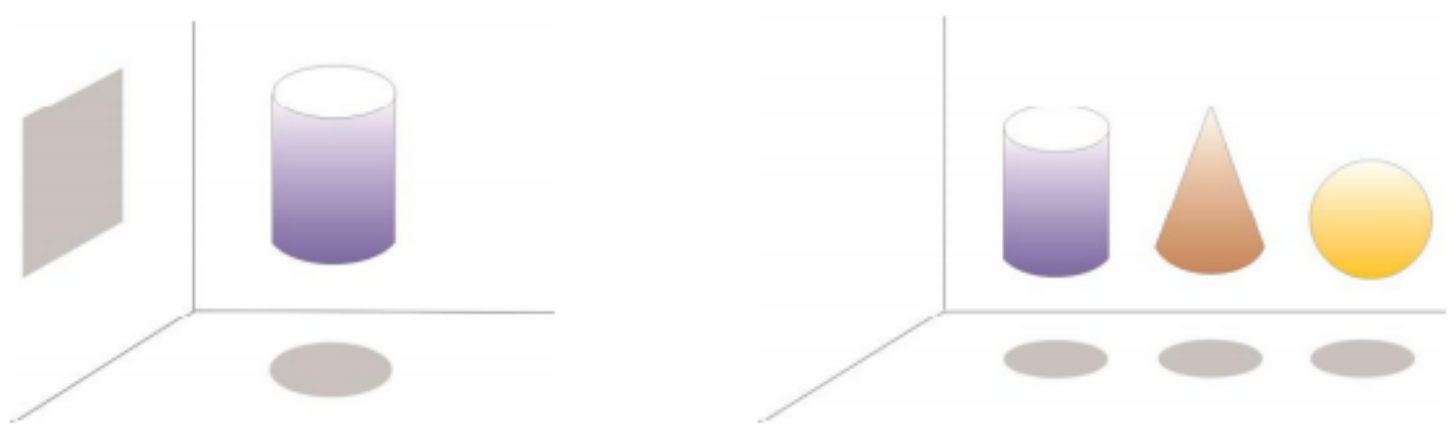

Figura 1 e 2: Fonte das autoras

A Logoterapia, portanto, insiste na abertura do ser humano para o mundo, pois ele possui esse carácter de autotranscendência. Miguez (2015, p. 10) afirma que para esse referido campo teórico "o homem é alguém que está sempre orientado e ordenado a algo que não é ele mesmo, seja uma tarefa a desempenhar, uma causa a defender, um encontro a consumar". Frankl (1991) compreende que o homem é um ser livre e responsável. Livre no sentido de, apesar de alguns fatores determinantes (historicidade, a família que possui, a sociedade em que vive, por exemplo), pode realizar escolhas diante das possibilidades apresentadas à sua existência. $O$ autor, durante a $2^{a}$ Guerra Mundial foi preso e sofreu os horrores da guerra em campos de concentração, entre eles esteve em Auschwitz. Essa terrível experiência Ihe permitiu dizer que foi nesse contexto que ele aprofundou ainda mais seu olhar sobre quem era o homem: "é aquele ser que inventou as câmaras de gás de Auschwitz; mas também é aquele ser que entrou naquelas câmaras de gás de cabeça erguida, tendo nos lábios o Pai-Nosso ou o Shemá Yisrael" (Frankl, 2004, p.114).

A experiência de Frankl nos campos de concentração reafirmou a tese que antes desse acontecimento ele já elucidava: a de que "a vida tem sentido de forma incondicional e sob qualquer circunstância" (Frankl, 2004 citado por Miguez, 2014, p.23). Frankl (2004) percebeu na prática que, os prisioneiros que conseguiam direcionar sua vida para um sentido - quando não eram direcionadas às câmaras de gás - possuíam mais chances de sobrevida.

Retomando o paralelo entre Kierkegaard e Frankl proposto nesse trabalho, podemos afirmar que o homem é o ponto central do pensamento de ambos os autores que nos convidam a refletir sobre vários questionamentos que permeiam a história da humanidade, dentre elas: o que é o homem, qual o sentido da sua existência? A seguir, abordaremos alguns aspectos existenciais caros aos dois autores, e que permitem ampliar nossa reflexão sobre o homem. 


\section{O desespero e a busca pelo sentido}

A partir da visão antropológica exposta anteriormente, Frankl (1991) entende que o homem precisa estar orientado para a busca do sentido de sua existência, caso contrário, instala-se um vazio existencial. Ao falarmos de vazio existencial em Frankl (1991), cabe retomarmos o conceito de desespero em Kierkegaard (2008). Para o autor dinamarquês, "(...) o desespero é um fenômeno do espírito, algo que se relaciona com o eterno e que, por conseguinte, contém algo eterno em sua dialética" (p.45). Chama a atenção a visão de Kierkegaard (2008) a respeito de o desespero ser algo que só é possível a partir da relação do homem com o eterno. O desespero seria, então, algo que possibilita ao homem o pensar no seu eu. O desespero é a fagulha do eterno, e só pode ser pensado se considerarmos "o homem dentro da categoria de espírito" (Kierkegaard, 2008, p.46).

A partir da visão kierkegaardiana podemos então afirmar que não desesperaríamos se não tivéssemos relação com o eterno. O autor afirma que todo ser humano é desesperado, até mesmo aquele que acha que não é. O desespero, ao contrário do que se pode pensar, não é algo raro, e sim "um fenômeno completamente universal" (Kierkegaard, 2008, p.47). O desespero não habita só naqueles que reconhecem estar desesperados, portanto. Até mesmo naqueles que não se reconhecem desesperados, estão desesperados, pois é inerente à condição humana.

É interessante a observação que Kierkegaard (2008) faz ao dizer que grande parte dos homens vive sem consciência do seu próprio eu, já que não admite ser constituída de espírito. Portanto, a questão do sentido da vida é sempre presente. Ainda mais em tempos em que não encontramos mais o sentido, ou acabamos por nos distanciar do nosso próprio 'eu', da dimensão espiritual humana, da nossa condição imanente de desespero. E o desespero, no sentido kierkegaardiano, é o que nos torna humanos, já que também nos impele a nos assumirmos enquanto espírito, enquanto 'eu' e guarda consigo a relação com o eterno no homem.

Kierkegaard (2008) afirma que:

(...) a eternidade te perguntará - com a cada um de todos os milhares e milhares de homens - somente por uma coisa: se viveu ou não viveu desesperado, e se desesperado, não suspeitaste que o eras, ou se levaste ocultamente esta enfermidade no mais profundo de si mesmo como o segredo devorador de sua vida ou como o fruto de um amor proibido apertado contra teu coração, ou talvez levaste de tal maneira que, sendo o espanto dos demais, não tendo mais que enfurecer-te em meio ao desespero (p.49). 
Assim, para Kierkegaard (2008, p.126), o desespero é ainda "um ato que exige toda a força da alma, toda sua seriedade e toda a sua concentração". Sem se desesperar, o homem não pode alcançar o conhecimento da importância da própria existência, já que ela não se encontra encerrada nos prazeres. Na visão kierkegaardiana, portanto, "o homem que desespera encontrará o homem eterno, e, neste, somos todos iguais" (Kierkegaard, 1986, p.127). O homem nesta visão, é, portanto, comprometido com sua própria existência, já que necessita sempre realizar escolhas.

O pensamento de Frankl (2003) se coaduna com o do autor dinamarquês, na medida em que, para ele, "não devemos perguntar pelo sentido da vida, porque somos nós mesmos que somos pela vida interrogados" (p.45-46). Ou seja, tanto para Kierkegaard (2008) como para Frankl (2003), a pergunta virá da vida, da eternidade, e somos livres e responsáveis para responder a tais questionamentos no momento em que realizamos nossas escolhas.

Frankl (1991) entende, portanto, que o homem precisa estar orientado para a busca do sentido de sua existência, caso contrário, instala-se um vazio existencial. 0 autor em sua análise ressalta que o vazio existencial foi um constructo muito estudado no século $X X$, atribuindo esse fato aos fatos históricos, já que o homem foi abandonando alguns de seus instintos animais básicos, e perdendo também as tradições firmadas pela cultura. Frankl (2004) elucida ainda que o sentido é pessoal, ou seja, diferente para cada sujeito; é também situacional, já que pode se modificar de um dia para outro e até mesmo de uma hora para outra. Segundo o autor, "o que importa, por conseguinte, não é o sentido da vida de um modo geral, mas antes o sentido específico da vida de uma pessoa em um dado momento." (p.63). Ele afirma que não devemos, portanto, procurar um sentido abstrato da nossa existência. Cada ser é único e irrepetível.

Assim, a tarefa de cada um é tão singular como a sua oportunidade específica de levá-la a cabo. Uma vez que cada situação na vida representa um desafio para a pessoa e lhe apresenta um problema para resolver, pode-se, a rigor, inventar a questão pelo sentido da vida. Em última análise, a pessoa não deveria perguntar qual o sentido da sua vida, mas antes deve reconhecer que é ela que está sendo indagada. Em suma, cada pessoa é questionada pela vida; e ela somente pode responder à vida respondendo por sua própria vida; à vida ela somente pode responder sendo responsável. Assim sendo, a logoterapia vê na responsabilidade (responsibleness) a essência propriamente dita da existência humana (Frankl, 2004, p.98-99).

\section{Liberdade, responsabilidade, possibilidade e necessidade}


Os conceitos de liberdade e responsabilidade adotados pela Logoterapia dialogam com os conceitos de possibilidade e necessidade formulados por Kierkegaard (2008). Para o filósofo dinamarquês, "para fazer-se alguém - e o eu há de fazer-se com toda liberdade - são igualmente essenciais a possibilidade e a necessidade" (p.57). A realidade é, portanto, a relação dialética entre possibilidade e necessidade. "A existência humana é desesperada sempre que falta a possibilidade" (Kierkegaard, 2008, p.59).

Até mesmo o conceito de desespero abordado por Kierkegaard, conforme apresentado anteriormente, é uma eleição, já que para o autor, "(...) não se pode desesperar sem eleger o desespero. E, ao desesperar, elege-se novamente. Que é o que se elege? Elege-se a si mesmo, não dentro da imediação, não como um indivíduo qualquer, mas elege-se a si mesmo em sua validade eterna" (Kierkegaard, 1986, p.128-129).

Na visão kierkegaardiana, portanto, as escolhas são fundamentais para a vida do homem. Nas palavras do autor, "o homem é aquilo que se torna: ele se faz, se elege e existe. Ele é responsável pela sua existência, vive interessado infinitamente por existir" (Kierkegaard, 1986, p.231). Além de o homem existir, a sua vida só alcança significado a partir do conhecimento de si. Para Kierkegaard (1986, p.236), consequentemente, "a verdade é a subjetividade". Nas palavras do autor: "O homem é aquilo que se torna: ele se faz, se elege e existe. Ele é responsável pela sua existência, vive interessado infinitamente por existir" (Kierkegaard, 1986, p.231).

Quando refletimos acerca da liberdade humana, encontramos em Kierkegaard (2007), a compreensão de que ao se perceber livre, o homem se depara também com a angústia. Para o filósofo dinamarquês:

A angústia pode ser comparada à vertigem. Quando o olhar imerge em um abismo, existe uma vertigem que nos chega tanto do olhar como do abismo, visto que nos seria impossível deixar de encará-lo. Esta é a angústia, vertigem da liberdade, que surge quando, ao desejar o espírito estabelecer a síntese, a liberdade imerge o olhar no abismo das suas possibilidades e agarra-se à finitude para não soçobrar (Kierkegaard, 2007, p. 74).

Ao pensarmos no problema filosófico da liberdade, podemos trazer aqui uma imagem curiosa: a do pássaro. O pássaro não é livre para voar, já que não é dotado de espírito, assim como os outros animais irracionais também não o são. Ele não pode escolher, portanto suas ações. Ele voa pelo fato de seu ciclo biológico o condicionar a voar. Com o ser humano, é justamente a esfera do espírito que lhe confere a possibilidade de escolha. Portanto, somos seres dotados de espírito, possuímos um eu, e à medida que tomamos mais consciência do nosso próprio eu, percebemos 
também nossa condição de desespero, que não pode ser evitado. Somos seres únicos, irrepetíveis, e por isso, livres (em certa medida), e responsáveis (capazes de responder às demandas da vida).

Miguez (2015) elucida a visão da Logoterapia e Análise Existencial que compreende que a liberdade humana atua apesar dos condicionamentos. O homem vive nessa dialética, já que "seu ser é continuamente um poder-ser" (p.73). O ser humano não é livre de certos condicionamentos existentes, e sim, livre para escolher apesar do que Ihe acontece. Portanto, para Frankl (2004, p.151), "a conduta do homem não é ditada pelas condições que ele encontra, mas pelas decisões que toma".

A responsabilidade é trazida à arena da questão existencial por Frankl (2004), que a apresenta como o outro cerne da metafísica da vontade livre. Para Miguez (2015), a liberdade, ou seja, a capacidade humana de "poder ser", é acompanhada pelo "dever-ser", ou seja, à sua capacidade de responder à vida, à sua responsabilidade.

(...) há algo terrível nela, mas, ao mesmo tempo, algo maravilhoso! É terrível saber que a cada momento sou responsável pelo momento seguinte; que cada decisão, da menor à maior, é uma decisão "para toda a eternidade"; que em todo momento estou realizando uma possibilidade, a responsabilidade desse momento único, ou a estou perdendo. (...) Mas é maravilhoso saber que o futuro, o meu e o das coisas que vêm com ele, o futuro dos homens ao meu redor, depende de alguma maneira - ainda que seja em grau insignificante - da decisão que eu tome a cada instante (Frankl, 1983, p.71-72, tradução nossa).

Somos seres que realizam, que se alegram, mas também somos seres que sofrem. Atualmente, as pessoas parecem querer negar essa dimensão do sofrimento, que é uma dimensão existencial essencialmente humana. Não percebem, porém, que ao negarem o próprio desespero, acabam por negligenciar o seu próprio eu, e distanciam-se de si mesmos. Nesse contexto, Frankl (2004) ajuda a pensar na necessidade de autotranscendência diante do desespero presente, da angústia, do vazio existencial, do sofrimento que parece vir sem dar explicação contundente e que pode ser compreendido e vivenciado sob a liberdade da vontade. Ambos os autores consideram, portanto, a liberdade do homem.

\section{Angústia e vazio existencial: o ser e o devir}

Após as considerações importantes acerca da liberdade, é fundamental retomar nosso olhar para a temática que Søren Kierkegaard ocupou-se na obra O Conceito de Angústia (1844). De acordo com Garaventa (2011, p.6), tal obra apresenta um estudo da "fenomenologia (...) deste estado afetivo fundamental da existência": a angústia. A 
angústia é aqui compreendida enquanto um desdobramento do fato de o homem perceber-se livre.

Garaventa (2011), apropriando-se dos pressupostos kierkegaardianos aponta que quando o homem se depara com a possibilidade de escolher a si mesmo, num total exercício de sua liberdade, ele é tomado, justamente por saber que existe um abismo com diversas escolhas possíveis de serem feitas, pela vertigem. Kierkegaard constrói sua obra sobre a angústia partindo do conceito de queda explicitado na passagem bíblica de Gêneses 3. Assim, a figura de Adão, porque é dotada de espírito, pôde angustiar-se, já que a capacidade de ser acometido pela angústia é uma característica do gênero humano. Nesse sentido, podemos compreender a angústia enquanto sintoma da própria condição humana de criatura, refletindo sobre a condição da fragilidade de sua existência, compreendendo, portanto, "a autoexperiência do Eu como espírito infinito, ainda que, ao mesmo tempo, ligado a finitude, à temporalidade, à corporeidade" (Garaventa, 2011, p.11).

A angústia de liberdade também é definida por Kierkegaard como "angústia do nada, quanto o indivíduo, no momento da escolha, encontra-se defronte ao seu nada, àquilo que ele não é ainda (já que só será 'alguma coisa' quando tiver feito a escolha)" (Garaventa 2011, p.6). Percebemos ainda na obra de Kierkegaard o que pressupõe Garaventa (2011, p.8), analisando que "o que produz a angústia é, portanto, o 'nada' que o indivíduo (na sua abertura e indeterminação) 'é' no momento de estabelecer a síntese, de tornar-se a si mesmo, de dar-se uma imagem e uma identidade precisas".

Miguez (2015) aponta que Frankl nomeou o vazio existencial de "síndrome de falta de sentido" (p.10), elucidando a angústia, o vazio, a falta de encontrar o sentido para a própria existência como sintomatologias presentes no bojo do pós-guerra. Entretanto, tal síndrome foi acentuada com a crise da modernidade a permanece mais atual do que nunca. Nossa sociedade hoje é composta por pessoas cada vez mais solitárias, que, na busca de encontrarem um refúgio para lidar com o vazio, escolhem o simbólico e a vida social. Para Frankl (2008):

O homem já não se compreende senão como um ser da natureza, segundo a atitude naturalista, e entende o mundo como nada mais que um meio para um fim, de acordo com a posição técnico-utilitarista. Assim submete o mundo pela técnica. Ao mesmo tempo, enquanto o mundo se converte para ele em objeto de submissão, transforma-se ele mesmo, o homem, em seu próprio "oposto": em objeto (p.88).

Søren Kierkegaard e Viktor Frankl nos ajudam a pensar nesses aspectos caros à existência humana. O 'eu' não está acabado, pronto. Pelo contrário, está sempre em devir. O devir é próprio do humano, que se constitui também a partir de sua história, 
de seus desejos, de suas emoções, afetos, de sua cognição, sede de saber, e de sua capacidade de liberdade e responsabilidade. A escolha por utilizar o termo devir se dá pelo fato de tal termo evidenciar o tornar-se, que é da ordem do processo. Devir, para Mora (2000):

(...) É usado às vezes como sinônimo de 'tornar-se'; às vezes é considerado o equivalente de 'vir a ser'; às vezes é empregado para designar de um modo geral o mudar ou o mover-se (que, além disso, costumam ser expressos por meio do uso dos substantivos correspondentes: 'mudança' e 'movimento'). Nessa multiplicidade de significações parece haver, contudo, um núcleo significativo invariável no vocábulo 'devir': é o que destaca o processo do ser, ou, se se quiser, o ser como processo (p.707).

O devir é, portanto, da esfera do espírito. O "eu" está sempre nesse processo dinâmico do devir. Miguez (2015) pontua que o devir, no âmbito da logoterapia, não deve ser compreendido enquanto "puro fluir" no sentido heraclitiano do termo, e sim no sentido aristotélico de definição entre potência e ato, "entendendo que o ato é anterior (ontologicamente) à potência, o que revela a unicidade do ser - ele se torna aquilo que realmente é em essência" (p.147). Kierkegaard e Frankl, portanto, nos permitem aguçar nossa consciência frente as escolhas e as possibilidades, e principalmente frente ao nosso próprio eu, e ao nosso processo de tornar-se humano. Porque o humano está em potência de se constituir naquilo que essencialmente é nas tramas da existência. A potência ainda não é ato; o homem pode, através da liberdade da vontade e da forma como decide responder à vida, acabar se distanciando do que essencialmente é.

É certo que se nasce com condicionamentos diversos tais como o de pertencimento a uma dada espécie, e que pode confundir-se com a massa, pode ser mais um na multidão. Porém, o homem possui a possibilidade de "tornar-se indivíduo" (Ponte, 2010, p. 48). Sobre isso, Kierkegaard (1986) pontua:

A multidão se compõe de indivíduos. Deve estar, pois, ao alcance de cada um tornar-se o que é: um indivíduo. Ninguém, ninguém em absoluto está excluído de tornar-se um indivíduo exceto aquele que se exclui de si mesmo, tornando-se multidão (p.169).

Autores pertencentes à Escola de Frankfurt como Adorno e Horkheimer (1985), Marcuse (1975) e Benjamin (1985) teceram críticas à sociedade tecnicista que serve aos interesses da indústria cultural, visando impor padrões de comportamento, ideológicos, de linguagem, da forma de ser e estar no mundo, de modo que o sujeito acaba por se conformar - entrar na forma - desses moldes, renunciando - muitas vezes de maneira inconsciente - à sua própria humanidade. O homem se misturou na 
massa, homogênea, sem qualquer possibilidade de liberdade verdadeira. O sujeito perdeu-se de sua condição, e igualou-se à de objeto. Obviamente o alvo da crítica em questão não estava na técnica em si, no desenvolvimento e aprimoramento de tecnologias, e sim na supervalorização da mesma em detrimento do próprio homem. A máquina passou a não estar mais a serviço do homem. O homem passou a servir a máquina.

No bojo da fragmentação do pensamento, da supremacia da técnica frente ao humano, de uma tentativa de homogenização da conduta humana, é preciso resistir. Resistir à fragmentação do próprio eu. Resistir a modelos reducionistas que acabam por excluir o que há de mais humano: a dimensão noética, o senso de liberdade da vontade, a responsabilidade do sujeito, a sua capacidade inventiva, os seus valores e a sua sede de sentido. O homem é um ser capaz de resistir, de fazer diferente, de encontrar sentido em meio ao seu próprio desespero.

Resgatamos o artigo de Silveira e Mahfoud (2008) que apresenta o conceito de resiliência como sendo a "capacidade humana para enfrentar, sobrepor-se e ser fortalecido ou transformado por experiências de adversidade" ou mesmo como "capacidade de enfrentar a dificuldade e sair fortalecidos desta prova" (p. 569). Miguez (2015) cita que o curioso é que Frankl, antes que as pesquisas sobre resiliência aparecessem no cenário científico, já desenvolvera ideia semelhante, a partir do seu experimentum crucis: "a força de resistência do espírito", entendida como a capacidade humana de opor-se (no sentido de "colocar-se diante de", "confrontar") às situações mais adversas e condições de opressão que acometem o homem. Em virtude do autodistanciamento - tema já analisado anteriormente - o homem é capaz de tomar distância não só de uma situação, mas também de si mesmo, o que lhe permite tomar posição com relação aos próprios condicionamentos biológicos, psicológicos e sociológicos (Frankl, 2005, p.23).

\section{Considerações Finais}

Compreendemos, portanto, que ao tomarmos como objeto de estudo algum fenômeno humano, no campo da filosofia ou mesmo da psicologia, precisamos nos dedicar à compreensão da dimensão do espírito e de quem de fato é o homem que nos propomos a conhecer. O ser humano é um ser em seu processo de tornar-se indivíduo, diferenciando-se da multidão. Está sempre em devir, em processo entre o ser e o dever ser. É um ser imerso no desespero, mesmo que não se dê conta de sua própria condição. É único e irrepetível. O humano é um ser nascente, dotado de espírito. Portanto, Kierkegaard e Frankl legitimam a esfera espiritual e, dessa maneira, abordam acerca do humano de uma maneira integral e plena de sentido. 
As concepções teóricas que desconsideram a dimensão espiritual do homem, acabam por apresentar uma visão reducionista ou "amputada" do próprio homem, negando, assim, sua totalidade. Assim, as questões existenciais só serão melhores investigadas e compreendidas na medida em que não excluirmos essa importante dimensão humana que é parte integrante e estruturante do eu.

Diante do mundo pós-moderno que parece viver sob a égide do individualismo, do materialismo, do consumo, da falta de sentido e da desesperança diante da vida, os pensamentos de Kierkegaard e de Frankl sobre o homem e os aspectos de sua existência ganham força e atualidade sendo capazes de provocar em nós o desejo de aprofundarmos nas questões essenciais que se apresentam em nossa própria existência referente a quem somos, de onde viemos, para onde vamos, e a respeito do próprio sentido da existência. Kierkegaard e Frankl viveram em épocas distintas, porém ambos perceberam, de algum modo, as distorções do sentido da vida presentes na sociedade. A partir do diálogo entre suas proposições, compreendemos que a vida humana só alcança sentido quando se consegue chegar a uma compreensão mais profunda do seu próprio ser, que nunca é um ser isolado, e sim, um ser-no-mundo.

\section{Referências}

Adorno, T. W. \& Horkheimer, M. (1985). A dialética do esclarecimento (G. A. Almeida, Trad.). Rio de Janeiro: Zahar.

Aquino, T. A. A. (2013). Logoterapia e análise existencial: uma introdução ao pensamento de Viktor Frankl. São Paulo: Paulus.

Aquino, T. A. A., Damásio, B. F., \& Silva, J. P. (2010). Logoterapia e educação: fundamentos e prática. São Paulo: Paulus.

Benjamin, W. (1985). Obras escolhidas: magia e técnica, arte e política (S. P. Rouanet, Trad.). São Paulo: Brasiliense.

Bessa, J. (2009). Kierkegaard: (1813-1855): vida e obra. 27 ago. 2009. Disponível em: <http://www.josemarbessa.com/2009/08/kierkegaard-1813-1855-vida-eobra.html>. Acesso em: 03 jun. 2017.

Dourado, E. T. S. e outros (2010). Educar para o sentido: uma intervenção prática. Em: T. A. A. Aquino, B. F. Damásio \& J. P. Silva (Org.s). Logoterapia e educação: fundamentos e prática (pp.79-138). São Paulo: Paulus.

Farago, F. (2006). Compreender Kierkegaard. Rio de Janeiro: Vozes. 
Frankl, V. E. (1978). Fundamentos antropológicos da psicoterapia (R. Bittencourt, Trad.). Rio de Janeiro: Zahar.

Frankl, V. E. (1983). Psicoanalisis y existencialismo: de la psicoterapia a la logoterapia de Viktor E. Frankl (C. Silva \& J. Mendoza, Trad.). México: Fondo de Cultura Económica.

Frankl, V. E. (1988). The Will to Meaning. New York: Meridian Books.

Frankl, V. E. (1991). Psicoterapia para todos (A. Allgayer, Trad.). Petrópolis: Vozes.

Frankl, V. E. (1995). Logoterapia e análise existencial: texto de cinco décadas (J. P. Santos, Trad.). Campinas: Editorial Psy II.

Frankl, V. E. (2003). A presença ignorada de Deus (W. O. Schlupp; H. H. Reinhold, Trad.). São Leopoldo: Sinodal.

Frankl, V. E. (2004). Em busca de sentido: um psicólogo no campo de concentração (W. O. Schlupp; C. C. Aveline, Trad.). Petrópolis: Vozes.

Frankl, V. E. (2005). Um sentido para a vida: psicoterapia e humanismo (V. H. Lapenta, Trad.). 11. ed. Aparecida: Ideias e Letras.

Frankl, V. E. (2010). O que não está escrito em meus livros: memórias (C. Abeling, Trad.). São Paulo: E Realizações.

Garaventa, R. (2011). Søren Kierkegaard: uma fenomenologia da angústia. Sacrilegens, 8(1), 5-19.

Gouvêa, R. Q. (2000). Paixão pelo paradoxo: uma introdução à Kierkegaard. Barueri, SP: Novo Século.

Kierkegaard, S. (1986). Textos selecionados (E. Reichmann, Trad.). Curitiba: Universidade Federal do Paraná.

Kierkegaard, S. (2007). O conceito de angústia (T. Guimarães, Trad.). São Paulo: Hemus.

Kierkegaard, S. (2008). La enfermedad mortal (D. G. Rivero, Trad.). Madrid: Editorial Tratta.

Lukas, E. (1989). Logoterapia: a força desafiadora do espírito. (J. S. Porto, Trad.). São Paulo: Loyola; Santos: Leopoldianum (Original publicado em 1987).

Marcuse, H. (1975). A ideologia da sociedade industrial (G. Rebuá, Trad.). Rio de Janeiro: Zahar. 
Miguez, E. M. (2014). Educação em busca de sentido: pedagogia inspirada em Viktor Frankl. São Paulo: Paulus.

Miguez, E. M. (2015). Educação em Viktor Frankl: entre o vazio existencial e o sentido da vida. Tese de Doutorado, Programa de Pós-graduação em Educação, Universidade de São Paulo, São Paulo, SP.

Miguez, E. M. (2019). Educação em Viktor Frankl: entre o vazio existencial e o sentido da vida. Curitiba: Brazil Publishing.

Mora, J. F. (2000). Dicionário de filosofia. 6. ed. São Paulo: Loyola.

Pereira, I. S. (2013). A ética do sentido da vida: fundamentos filosóficos da logoterapia. Aparecida: Ideias e Letras.

Pereira, I. S. (2015). A ontologia dimensional de Viktor Frankl: o humano entre corpo, psiquismo e espírito. Logos e Existência, 4(1), 2-13.

Ponte, C. R. S. (2010). Sobre os conceitos de indivíduo em Sören Kierkegaard e de pessoa em Carl Rogers: semelhanças e diferenças. Dissertação de Mestrado, Programa de Pós-graduação em Psicologia, Universidade Federal do Ceará, Fortaleza, CE.

Silveira, D. R. \& Mahfoud, M. (2008). Contribuições de Viktor Emil Frankl ao conceito de resiliência. Estudos de Psicologia, 25(4), 567-576.

Vaillant, G. E. (2010). Fé: evidências científicas (I. Alves, Trad.). Barueri, SP: Manole.

Volkmer, S. A. J. (2006). O perceber do valor na ética de Max Scheler. Dissertação de Mestrado, Programa de Pós-Graduação em Filosofia, Pontifícia Universidade Católica do Rio Grande do Sul, Porto Alegre, RS.

\section{Nota sobre os autores}

Glenda Matias de Oliveira Rosa é psicóloga pela Universidade Federal de Uberlândia. Mestra pelo Programa de Pós-Graduação em Processos do Desenvolvimento e Saúde da Universidade de Brasília. Atualmente, é doutoranda pelo Programa de Pós-Graduação em Psicologia do Desenvolvimento e Escolar do Instituto de Psicologia da Universidade de Brasília. E-mail: glendapsico@gmail.com

Lúcia Helena Cavasin Zabotto Pulino é psicóloga pela Faculdade de Filosofia, Ciências e Letras de Ribeirão Preto - Universidade de São Paulo. Mestra em Lógica e Filosofia pela Universidade Estadual de Campinas e doutora em Filosofia pela mesma universidade. Professora-associada do Instituto de Psicologia da Universidade de Brasília. E-mail: Iuciahelenaczp@gmail.com 
Data de recebimento: $08 / 10 / 2018$

Data de aceite: 11/12/2019 